\title{
Curling of New Concrete Pavement and Long-Term
} Performance

\author{
Daba S. Gedafa ${ }^{1}$, M. Hossain ${ }^{2}$, Z. Q. Siddique ${ }^{3}$, K. Fredrichs ${ }^{4}$ and D. Meggers ${ }^{5}$ \\ 1.University of North Dakota, 243 Centennial Dr Stop 8115, Grand Forks, ND 58202-8115, USA \\ 2. Department of Civil Engineering, 2118 Fiedler Hall, Kansas State University, Manhattan, KS 66506, USA \\ 3. ARCADIS LNW, 420 Columbia Drive, Suite 110, West Palm Beach, FL 33409, USA \\ 4. FHWA Kansas Division, 6111 SW 29th St., Topeka, KS 66614, USA \\ 5. Bureau of Materials \& Research, Kansas Department of Transportation, 2300 Van Buren, Topeka, KS 66611, USA
}

\begin{abstract}
Curling results from the temperature differential across the concrete slab thickness and may induce undue stresses in newly placed slab. This study deals with the finite element (FE) analysis of curling, curling stresses, field measurement of curling on a newly built jointed plain concrete pavement, and comparison of its long-term performance using both Mechanistic-Empirical Pavement Design Guide (MEPDG) and HIPERPAVII software. The FE analysis was performed with a software program, ANSYS. The test section was modeled as a three-layer system with $300 \mathrm{~mm}$ concrete slab, $100 \mathrm{~mm}$ treated drainable base, and $150 \mathrm{~mm}$ lime-treated subgrade. All layers were assumed to be linear elastic. Temperature data was collected at five different depth locations across the concrete slab with digital data loggers. Curling was measured on five different days with a simple setup. The effect of temperature nonlinearities across the slab thickness was also examined. The results show that both upward and downward curling increase as the temperature differential increases. The maximum stress resulting from the combined effect of curling and traffic loading due to positive temperature differential is higher than that due to the negative temperature differential of the same magnitude. Since temperature differential has a significant influence on curling, both curling and curling stresses can be mitigated at an early age with temperature control, namely via enhanced curing. Both MEPDG and HIPERPAVII showed approximately the same performance for the PCC thickness ranging from $215 \mathrm{~mm}$ to $300 \mathrm{~mm}$ for this project. Performance prediction from HIPERPAVII is very sensitive to the change in PCC thickness less than $230 \mathrm{~mm}$ whereas MEPDG prediction is not as sensitive to the thickness change as with HIPERPAV II.
\end{abstract}

Key words: Curling, HIPERPAVII, long-term performance, MEPDG.

\section{Introduction}

The American Concrete Institute [1] defined curling as "the distortion of any essentially linear or planar member into a curved shape such as the warping of a slab due to creep or to differences of temperature or moisture content in the zones adjacent to its opposite faces." Curling is caused by the temperature gradient across the thickness of the concrete slab. It induces stresses in the pavement concrete slab since the slab is restrained by its weight and the support pressure from

Corresponding author: Daba S. Gedafa, PhD, P.E., assistant professor, research fields: mechanistic-empirical design, pavement management system, non-destructive testing, materials engineering, traffic engineering. E-mail: daba.gedafa@engr.und.edu. the foundation layer. The thermally induced stresses caused by such interaction can be a significant factor in contributing to early pavement cracking [2]. This may be critical, particularly a few hours after placement of the slab, since concrete at an early stage of hydration may have insufficient strength to prevent cracking. Temperature rise caused by hydration does not immediately produce thermal stresses because of the process of stress relaxation or creep in the concrete [3]. The temperature gradient in the newly placed slabs may cause the slabs to curl and even if the cracks do not develop, this gradient can cause curling, and permanent set of the concrete slabs in a non-planar fashion. This phenomenon is popularly known as "as-built” curling [4]. Studies have shown that this as-built curling 
adversely affects the future performance of jointed plain concrete pavement (JPCP) [4-5].

Traditionally, in the design and analysis of concrete pavements, the temperature distribution across the slab thickness is assumed to be linear. Unless actual field measurements are made, it is reasonable to assume a maximum temperature gradient of 0.055 to $0.077^{\circ} \mathrm{C} / \mathrm{mm}$ of slab during the day and about half of these values at night [6]. Studies have shown that for the temperature range encountered in a temperate region, the assumption of linear temperature profile could lead to errors of $30 \%$ or more in the computed peak warping stresses [7]. Zhang et al. [8] reported that assumption of linear temperature distribution overestimated tensile stresses during certain periods of the day, while underestimated during other periods. Differences between the peak tensile stresses corresponding to the linear and nonlinear analyses reached as high as $75 \%$. From field measurements, it is known that the temperature distribution is nonlinear. Typically, the nonlinear profile is featured with a relatively rapid change of temperature within the top quarter of the slab thickness, followed by a more gradual change towards the bottom face [9]. Researchers have represented non-linear temperature profile by a quadratic equation or by a third-order polynomial [7-8].

\section{Objectives}

The main objective of this study was to evaluate curling and curling stresses of JPCP by the finite element (FE) method as well as to compare these results with the curling measured in the field. Comparison of the long-term performance of this JPCP based on the MEPDG software and HIPERPAVII has also been done.

\section{Test Section and Data Collection}

The concrete pavement section in this study is located on Interstate route 70 (I-70). The section is a dowelled JPCP with $5 \mathrm{~m}$ joint spacing. The cross section consists of a $300 \mathrm{~mm}$ concrete slab, a $100 \mathrm{~mm}$ treated drainable base, also known as Bound Drainable Base (BDB) and a $150 \mathrm{~mm}$ lime-treated subgrade (LTSG). The BDB layer has a minimum permeability of $330 \mathrm{~m} /$ day. The concrete mixture was composed of $40 \%$ coarse and $60 \%$ fine aggregates with a water-cement ratio of 0.45 . The entrained air was $5.8 \%$. Average 28-day core compressive strength and 3-day modulus of rupture were $35.9 \mathrm{MPa}$ and $4 \mathrm{MPa}$, respectively.

Temperature data was collected by the digital data logger, iButton ${ }^{\circledR}[10]$. iButton ${ }^{\circledR}$ is a computer chip enclosed in a $16 \mathrm{~mm}$ stainless steel can. The assembly was installed near the right wheel path, which was about $1 \mathrm{~m}$ away from the edge of the driving lane. Temperature data was collected at five different depths across the slab thickness: the top surface, $75 \mathrm{~mm}, 150$ $\mathrm{mm}$, and $225 \mathrm{~mm}$ below the top surface; and the bottom surface. Data was collected at 10-minute intervals. The advantage of using five buttons is that they capture the actual temperature distribution across the slab thickness. Fig. 1 presents a typical hourly pavement temperature distribution curve. It is apparent from the figure that the temperature distribution is nonlinear. The nonlinearity for the bottom half of the slab is not as pronounced as it is for the top half. For the bottom half, the distribution is almost linear. For the top half, the distribution for the hours of positive temperature differential (i.e., temperature of the top surface is higher than that of the bottom) is steeper than that for the hours of negative temperature differential (i.e., temperature of the bottom is higher than that of the top). The hourly variation of temperature at the bottom of the slab is not much prominent. The difference between the maximum and the minimum temperatures is about $4.5^{\circ} \mathrm{C}$ for this particular case. However, this difference is more pronounced at the top surface, which is about $19^{\circ} \mathrm{C}$.

\subsection{Field Measurement of Curling}

Curling deflection of the study section was also measured by a simple set up. The schematic of this set 
up is shown in Fig. 2. It consists of an extensometer placed at the center of a lightweight aluminium frame. The length of the frame is approximately $5 \mathrm{~m}$, which represents the length of the concrete slab. The frame is positioned on steel pins attached to the bottom of the frame. These pins ensure correct and repeatable positioning, and serve to form a reference level. The pavement surface moves vertically with time because of the temperature differential between the pavement top and bottom surfaces. The extensometer, which is in contact with the top surface of the pavement, moves with the vertical movement of the concrete slab, thus measuring both upward and downward movements. This measurement represents the curling or mid-slab deflection of the pavement slab with respect to the reference plane established by the pins.

Data was collected on five different days. For a particular day, hourly curling measurements were taken throughout the day. Table 1 shows measured curling deflections as well as corresponding temperature differential between the slab top and bottom.

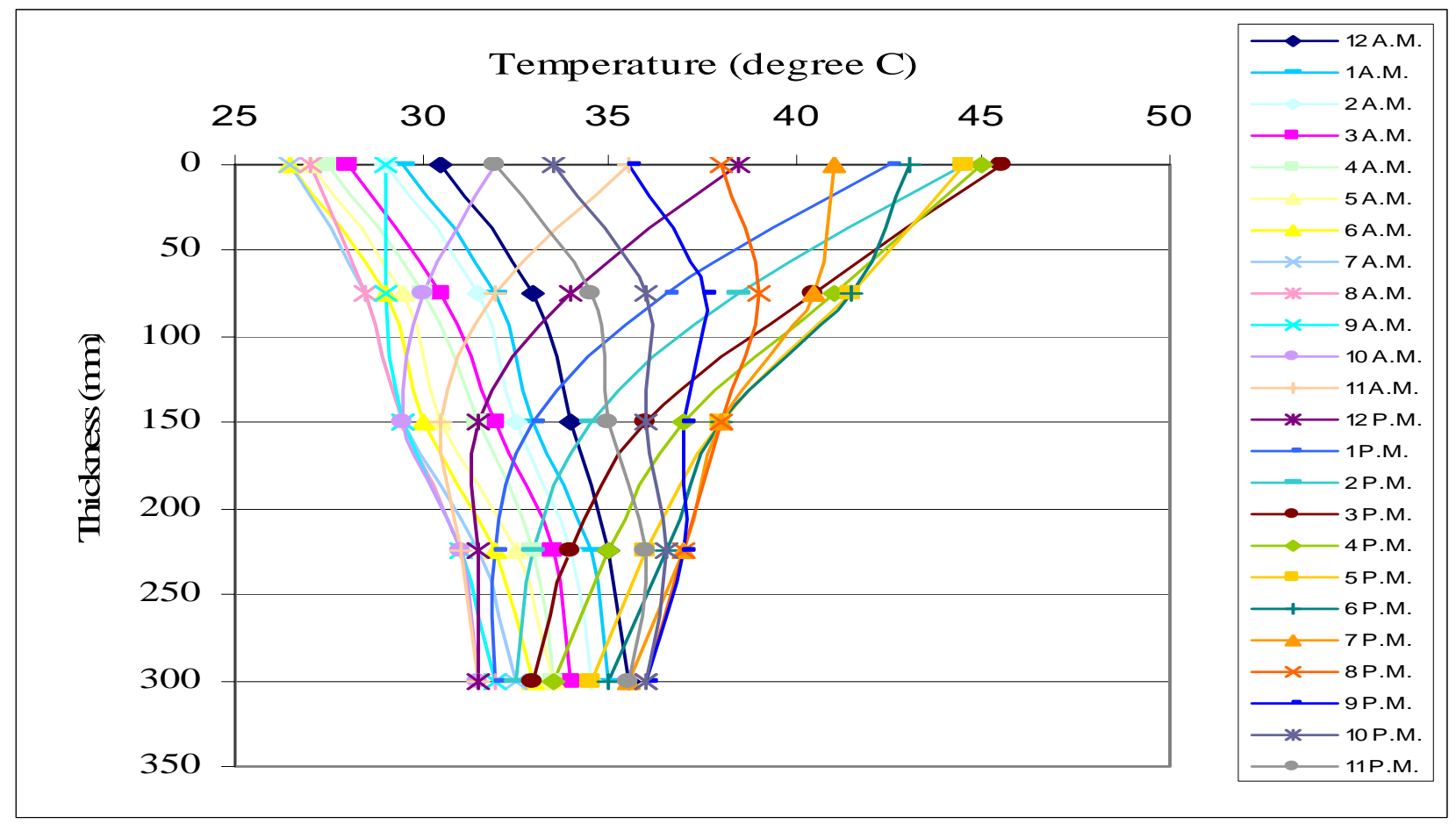

Fig. 1 Typical temperature variation across the slab thickness.

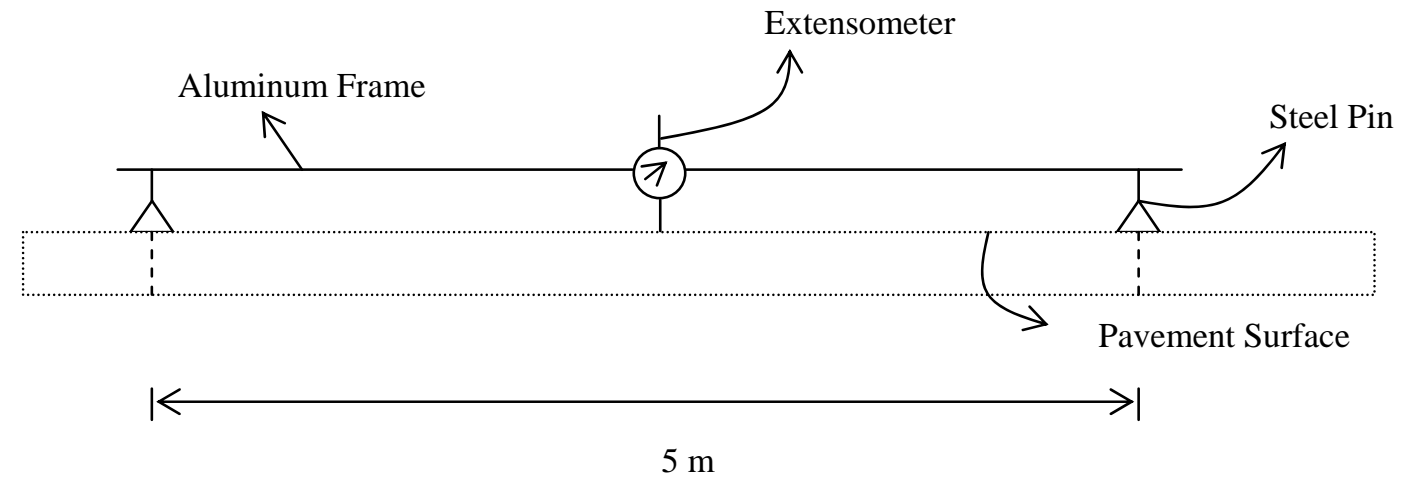

Fig. 2 Curling measurement. 
Table 1 Curling deflection and temperature differential values.

\begin{tabular}{cccccccccccc}
\hline & \multicolumn{2}{c}{ August 7 } & \multicolumn{2}{c}{ September 2} & \multicolumn{2}{c}{ September 25 } & \multicolumn{2}{c}{ October 15 } & \multicolumn{2}{c}{ November 6 } \\
\cline { 2 - 10 } Day Time & $\begin{array}{c}\text { Curling } \\
(\mathrm{mm})\end{array}$ & $\begin{array}{c}\text { Tem. } \\
\text { Diff. } \\
\left({ }^{\circ} \mathrm{C}\right)\end{array}$ & $\begin{array}{c}\text { Curling } \\
(\mathrm{mm})\end{array}$ & $\begin{array}{c}\text { Temp. } \\
\text { Diff. } \\
\left({ }^{\circ} \mathrm{C}\right)\end{array}$ & $\begin{array}{c}\text { Curling } \\
(\mathrm{mm})\end{array}$ & $\begin{array}{c}\text { Temp } \\
\text { Diff. } \\
\left({ }^{\circ} \mathrm{C}\right)\end{array}$ & $\begin{array}{c}\text { Curling } \\
(\mathrm{mm})\end{array}$ & $\begin{array}{c}\text { Tem. } \\
\text { Diff. } \\
\left({ }^{\circ} \mathrm{C}\right)\end{array}$ & $\begin{array}{c}\text { Curling } \\
(\mathrm{mm})\end{array}$ & $\begin{array}{c}\text { Temp. } \\
\text { Diff. } \\
\left({ }^{\circ} \mathrm{C}\right)\end{array}$ \\
\hline 8 A.M & - & -5.0 & -0.051 & -5.0 & -0.025 & -6.5 & - & -5.5 & - & -4.5 \\
9 A.M. & -0.025 & -3.0 & -0.013 & -3.0 & -0.025 & -4.0 & -0.076 & -4.5 & -0.051 & -4.5 \\
10 A.M. & -0.076 & 0.5 & -0.010 & -0.5 & -0.051 & -1.5 & -0.051 & -1.0 & -0.076 & -2.5 \\
11 A.M. & -0.051 & 4.0 & -0.051 & 1.5 & -0.051 & 1.5 & -0.051 & 2.5 & -0.024 & 0.0 \\
12 P.M. & 0.025 & 7.0 & 0.051 & 5.5 & 0.051 & 4.5 & 0.076 & 5.5 & -0.025 & 2.5 \\
1 P.M. & 0.279 & 10.5 & 0.203 & 9.0 & 0.229 & 6.5 & 0.229 & 7.0 & 0.076 & 5.0 \\
2 P.M. & 0.356 & 12.0 & 0.330 & 11.5 & 0.381 & 8.0 & 0.330 & 8.0 & 0.178 & 6.5 \\
3 P.M. & 0.635 & 12.5 & 0.584 & 13.0 & 0.457 & 8.5 & 0.432 & 8.5 & 0.356 & 7.0 \\
4 P.M. & 0.533 & 11.5 & 0.508 & 13.5 & 0.508 & 8.0 & 0.406 & 7.5 & 0.330 & 6.0 \\
5 P.M. & 0.457 & 10.0 & 10.406 & 12.0 & 0.381 & 6.5 & 0.406 & 6.0 & 0.279 & 4.0 \\
6 P.M. & 0.381 & 8.0 & 0.330 & 9.5 & 0.356 & 4.0 & 0.305 & 4.0 & 0.229 & 1.0 \\
7 P.M. & 0.330 & 5.5 & 0.330 & 6.5 & 0.279 & 1.5 & - & 2.0 & - & -1.5 \\
\hline
\end{tabular}

* Negative sign indicates upward curling.

\section{Methodology}

\subsection{Finite Element (FE) Modeling}

In this study, ANSYS 7.0 was used to simulate curling. The model was built with actual geometric and material properties of the JPCP section described earlier. The FE model was built for a three-layer system. Each lane is $3.7 \mathrm{~m}$ wide, whereas the widths of the inside and outside shoulders are $1.8 \mathrm{~m}$ and $3 \mathrm{~m}$, respectively. All lanes and shoulders are separated by longitudinal joints with a width of $9.5 \mathrm{~mm}$ and a depth equal to the quarter of the slab thickness. Transverse joints in the model are located at $5 \mathrm{~m}$ intervals and the dimensions are the same as those of the longitudinal joints. Cracks developing along the slab edge under the transverse joints were also modeled. Dowel bars, located at the mid-depth of the slab with a bar diameter of $37.5 \mathrm{~mm}$ and length of $450 \mathrm{~mm}$, were placed at 300 $\mathrm{mm}$ intervals. Because of the symmetry in the longitudinal (driving) direction, one half of the slabs on both sides of a transverse joint were used as the model geometry.

Element selection is important to obtain reasonable results in the FE analysis. Based on the experiences of previous researchers [11-13], a 3-D 20-node brick element was selected as the candidate element for this study. In the ANSYS library, this element is known as SOLID186. The interaction between concrete and dowel bars is a complex one. This interaction was modeled as a contact problem. Rigid-to-flexible type of contact, available in the ANSYS library, was used in "surface-to-surface" contact mode. Target element TARGE170 and contact element CONTA174 were selected to model the target and contact surfaces, respectively.

Concrete layer material was modeled as linear elastic. The effect of concrete slab on curling is overwhelming compared to the effects due to the base and subgrade layers. Hence, base and lime-treated subgrade layers were also modeled as linear elastic. Material properties needed for the FE model include the elastic properties, such as, modulus of elasticity and Poisson's ratio of different layers. Modulus of elasticity of concrete slab, drainable base, and subgrade layers used in this study were 29 GPa, 6.6 GPa, and 276 $\mathrm{MPa}$, respectively. Poisson's ratios for the concrete, $\mathrm{BDB}$, and lime-treated subgrade layers were assumed to be $0.15,0.15$, and 0.20 , respectively. The modulus of elasticity and the Poisson's ratio for the dowel bars were assumed as $200 \mathrm{GPa}$ and 0.25 , respectively. Since this study deals with curling, which is caused by 
temperature, another important material property that was needed is the coefficient of thermal expansion. The typical values of 9 microstrains $/{ }^{\circ} \mathrm{C}$ and 12 microstrains $/{ }^{\circ} \mathrm{C}$ were used as the coefficients of thermal expansion for concrete and steel, respectively.

Generating an FE mesh is an important part of FE modelling. Finer meshes produce better results. However, several factors, such as, size and complexity of the geometry, use of contact elements, and product limitation of the ANSYS version used in this study, restricted the creation of a very fine mesh. Fig. 3 shows the meshed geometry of the study section. In general, the mesh is coarse. However, because of discontinuities created by the joints in the slab, areas near the joints were refined to obtain better results. The total number of elements generated for each model was approximately 30,000. Temperature was used as the main load. Temperature data was applied with both linear and non-linear temperature distribution across the slab thickness. The bottom of the subgrade layer was assumed to be fixed in all directions. The edges of the base and subgrade layers were fixed in the z-direction (direction of traffic). Pavement edge was allowed to move in all directions. Both translation and rotation of the dowel bar were restrained in all directions on one side of the joint.

\subsection{Long-Term Performance Using MEPDG and HIPERPAVII}

Comparison of long-term performance using MEPDG and HIPERPAVII has been done. The two methods have been described separately.

\subsubsection{MEPDG}

The design methodologies in all versions of the AASHTO Guide are based on the empirical performance equations developed using the AASHO Road Test data from the late 1950s. Due to the limitations of earlier guides, a design guide, based as fully as possible on mechanistic principles, was developed under the National Cooperative Highway Research Program (NCHRP) [14]. The guide is popularly known as Mechanistic Empirical Pavement Design Guide (MEPDG). The procedure is capable of developing mechanistic-empirical design while accounting for local environmental conditions, local materials, and actual highway traffic distribution by means of axle load spectra. The designer first considers site conditions (traffic, climate, and material properties) in proposing a trial design for a new pavement. The trial design is then evaluated for adequacy against some predetermined failure criteria. Key distresses are predicted from the computed structural responses of stress, strain and deflection due to given traffic and environmental loads. If the design does not meet desired performance criteria, it is revised and the evaluation process is repeated as necessary [14].

The hierarchical approach is used primarily for traffic, materials, and environmental inputs in MEPDG. This approach provides the designer with several levels of "design efficacy" that can be related to the class of highway under consideration or to the level of reliability of design desired. In general, three levels of inputs are provided. Input data used for the MEPDG analysis of concrete pavements are categorized as: (1) General information; (2) Traffic; (3) Climate; (4) Pavement structures; and (4) Miscellaneous. The key outputs are the individual distress quantities. The outputs for JPCP are roughness in terms of international roughness index (IRI), percent slabs cracked, and joint faulting at the required level of reliability for a given design period

\subsubsection{HIPERPAVII}

HIPERPAV (HIgh PERformance concrete PAVing) is a Window-based concrete paving software. It was originally developed by the Transtec Group, Inc. for the Federal Highway Administration (FHWA) to serve as a tool in the proper selection and control of the factors affecting concrete pavement behavior at early age. By controlling these factors properly, one can ensure good performance of concrete pavement throughout its design life. It is the first software of its kind to provide control over the concrete pavement 


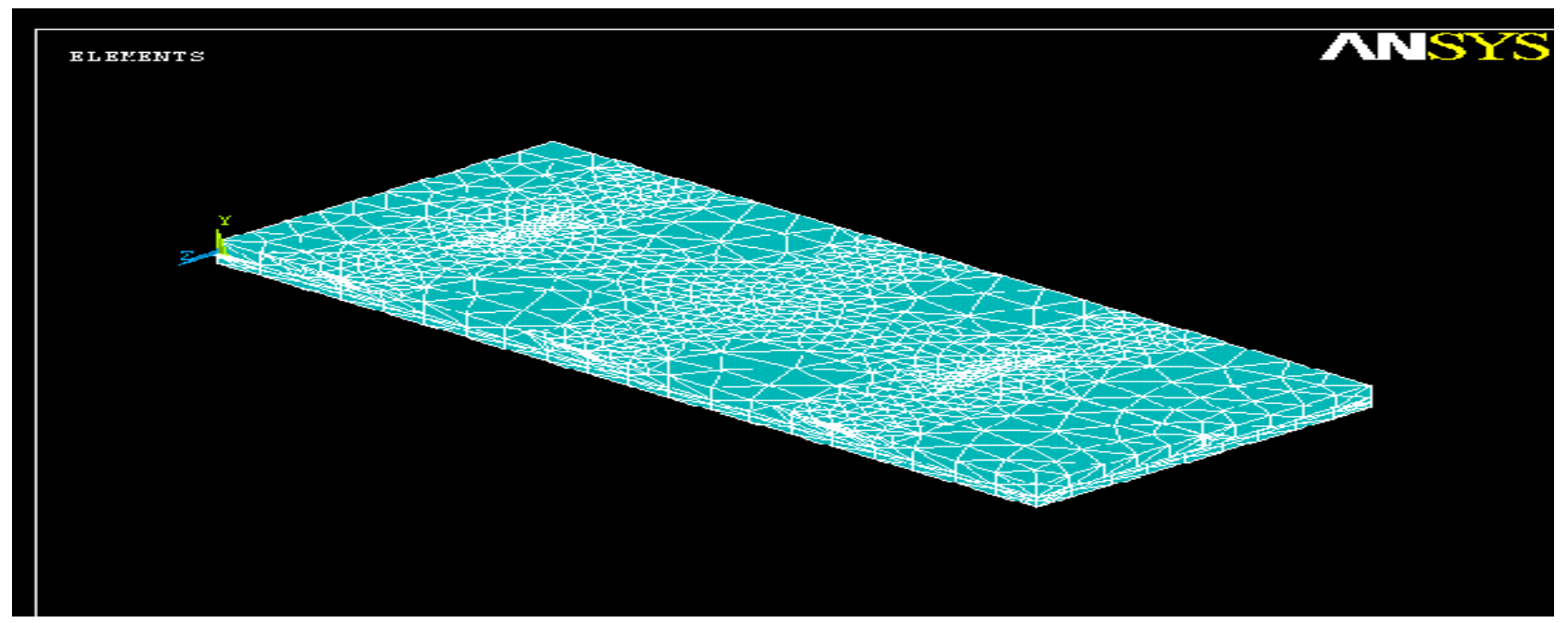

Fig. 3 Meshed geometry.

design and construction. It deals with the analysis of behavior of concrete pavement in the first 72 hours period after placement of both jointed plain concrete pavement (JPCP) and continuously reinforced concrete pavement (CRCP). In addition, the software determines the effect of early-age behavior factors on long-term performance of JPCP [15].

Some of the main inputs in HIPERPAVE II for analysis of JPCP are design (geometry, dowels and slab support), materials and mix design (type of cement, PCC mix, PCC properties, and maturity data), construction, environment, and traffic loading. Traffic loading is used only for long-term performance analysis. Each of these inputs has its own detailed components. The outputs for early-age JPCP are critical stress, evaporation rate, and dowel analysis results. The outputs for the long-term performance are joint faulting, transverse cracking, longitudinal cracking, ride (in terms of IRI), and serviceability. Longitudinal cracking and serviceability results have not been used in this study since there are no corresponding MEPDG outputs.

\section{Results and Discussions}

\subsection{FE Simulation}

Six different positive and negative temperature gradients simulating day and night time temperature differentials were applied to the FE model. In this study, positive temperature differential refers to the daytime condition when temperature of the slab surface is higher than that of the bottom surface. The opposite is true for the negative temperature differential. The applied temperatures were: $-5.6^{\circ} \mathrm{C},-2.8^{\circ} \mathrm{C},+2.8^{\circ} \mathrm{C}$, $+5.6^{\circ} \mathrm{C},+8.3^{\circ} \mathrm{C}$, and $11.1^{\circ} \mathrm{C}$. As expected, pavement slabs curled downward and upward for the positive and negative temperature differentials, respectively. Fig. 4 shows the curled profiles of the section for these temperature gradients assuming linear temperature distribution across the slab thickness. Both upward and downward curling deflections increased with an increase in temperature differential. Maximum deflection of $0.30 \mathrm{~mm}$ was obtained when the temperature differential was the maximum, which is $11.1^{\circ} \mathrm{C}$. However, curling deflection from a temperature differential of $11.1^{\circ} \mathrm{C}$ was not twice that due to a temperature differential of $5.6^{\circ} \mathrm{C}$, but was about $75 \%$ higher. The magnitude of the curling deflection for the same positive and negative temperature differential was not the same. A positive temperature differential resulted in higher magnitude of curling. The magnitudes of the upward curling were about $74 \%$ and $80 \%$ of downward curling for temperature differentials of $+2.8^{\circ} \mathrm{C}$, and $+5.6^{\circ} \mathrm{C}$, respectively. 


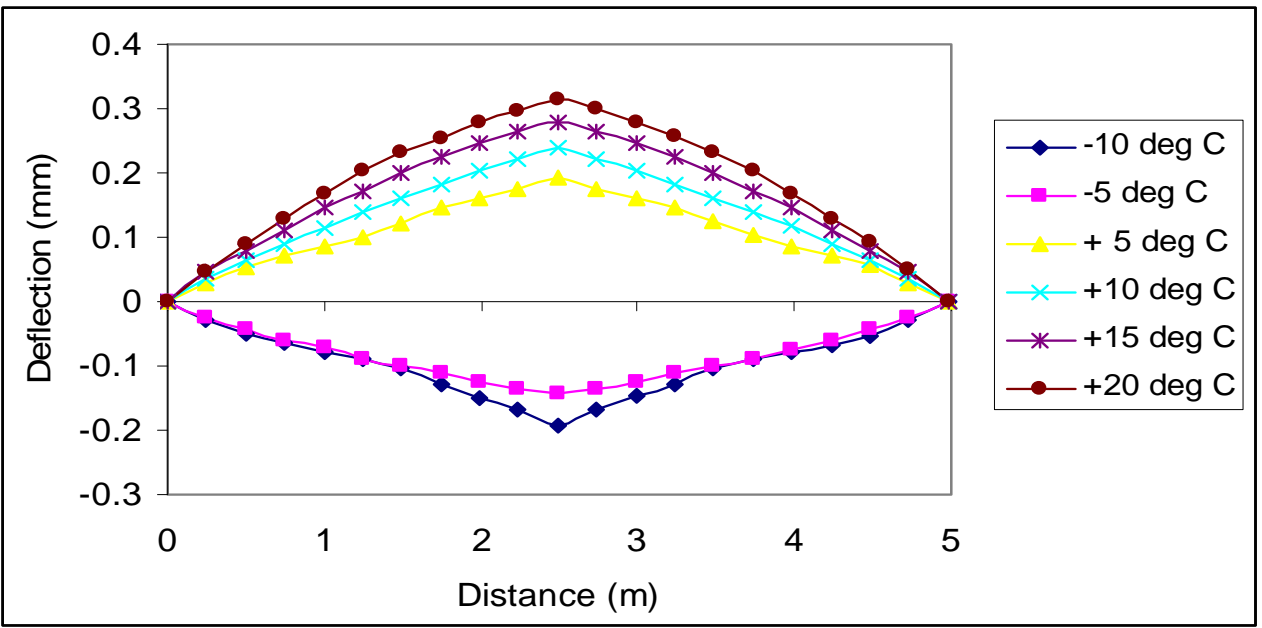

Fig. 4 Deflection profiles of the study section.

\subsection{Curling Stress}

It has long been recognized that critical stresses in concrete pavements result from the combined effects of curling and traffic loads. The location of traffic load also affects the critical stresses. In this study, the effect of truck loading in conjunction with the temperature loading was examined. An $80 \mathrm{kN}$ static load (two 40 $\mathrm{kN}$ ) loads at $1.8 \mathrm{~m}$ apart) was used in the analysis. Three different load positions on the pavement slab were investigated: (1) center, (2) edge, and (3) corner. A preliminary analysis showed that for positive temperature differential, the critical load position is at the edge of slab. On the other hand, for negative temperature differential, corner loading is the critical load position. Table 2 shows the maximum stresses due to the combined effect of temperature and traffic loading for the critical load locations. The results show that for both positive and negative temperature differentials, maximum curling stresses increase with an increase in temperature differential. Maximum stresses resulted from the combined effect of temperature and traffic loading due to a positive temperature differential is higher than those due to the same negative temperature differential. The difference between the combined stress due to curling and traffic, and the curling stress increases with an increase in the temperature differential.
Table 2 Maximum stresses due to combined effect of temperature and traffic load.

\begin{tabular}{|c|c|c|c|}
\hline \multirow{2}{*}{$\begin{array}{c}\text { Temperature } \\
\text { differential } \\
\left({ }^{\circ} \mathrm{C}\right)\end{array}$} & \multicolumn{3}{|c|}{ Maximum stress $(\mathrm{kPa})$} \\
\hline & $\begin{array}{c}\text { Curling } \\
\text { only }\end{array}$ & $\begin{array}{c}\text { Curling + } \\
\text { traffic } \\
\text { loading } \\
\end{array}$ & Difference \\
\hline-2.8 & 442 & 1090 & 648 \\
\hline-5.6 & 559 & 1366 & 807 \\
\hline 2.8 & 462 & 1290 & 828 \\
\hline 5.6 & 607 & 1628 & 1021 \\
\hline 8.3 & 683 & 1911 & 1228 \\
\hline
\end{tabular}

5.3 Linear Versus Non-Linear Temperature Distribution

In this study, the effect of linear and non-linear temperature distributions on curling was examined by FE method. Applied temperatures at the top and bottom for both analyses were the same. For nonlinear analysis, iButton temperatures were used to model nonlinear temperature distribution. Different temperature gradients ranging from $-5.6^{\circ} \mathrm{C}$ to $+13.9^{\circ} \mathrm{C}$ were used to compare the effects of linear and non-linear temperature distributions. Fig. 5 shows the maximum curling deflections due to different temperature differentials for linear and non-linear temperature distributions. For both positive and negative temperature gradients, maximum deflections resulting from linear temperature distribution are lower than those obtained from non-linear distribution. The 
difference in curling for linear and non-linear temperature distribution is about of 3 to $5 \%$.

\subsection{Comparison of FE and Field Measurement}

Fig. 6 shows the comparison of curling deflections obtained from the field measurements and the FE simulation. As mentioned earlier, during curling measurement on any given day, it was assumed that the slab was flat during the first measurement. Subsequent measurements were done hourly. Hence, these measurements showed the curling deflection of the section with respect to the first measurement. The finite element analysis was performed using the actual temperature condition during curling measurements. Results from both methods show similar trend, although actual values are different. Deflections obtained by the FE simulation were lower than those measured in the field. Better agreements were observed for lower temperature differentials. However, the difference increased with an increase in temperature differential.

\subsection{Comparison of Long-Term Performance Using MEPDG and HIPERPAVII}

The thickness of PCC has been varied from $150 \mathrm{~mm}$, which is the minimum allowable thickness using MEPDG, to original PCC thickness of $300 \mathrm{~mm}$ to compare the long-term performance at the end of 20 years using both MEPDG and HIPERPAVII. Long-term performance has been compared in terms of IRI (with minimum and maximum values of $0.99 \mathrm{~m} / \mathrm{km}$ and $2.59 \mathrm{~m} / \mathrm{km}$, respectively), percent slabs cracked (maximum 15\%), and mean joint faulting with terminal value of $3 \mathrm{~mm}$. The maximum limits have been indicated on the figures. Comparison based on these performance criteria has been done separately.

\subsubsection{IRI}

Fig. 7(a) illustrates the roughness development using

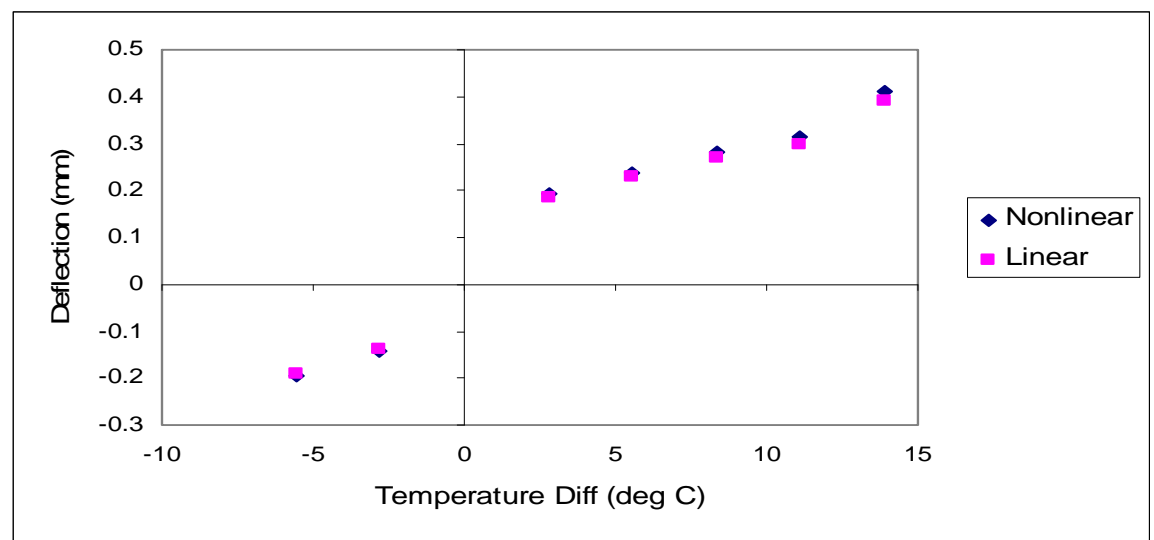

Fig. 5 Variation of curling with temperature differential.

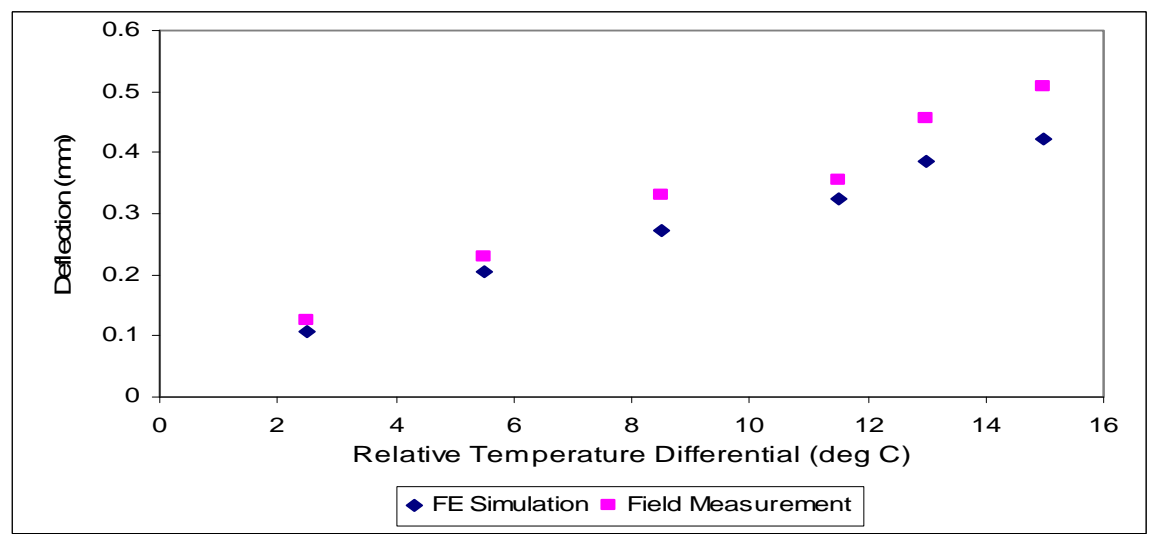

Fig. 6 Comparison of FE simulation and field measurement. 
both MEPDG and HIPERPAVII. The change in roughness due to change in thickness from $300 \mathrm{~mm}$ to $150 \mathrm{~mm}$ is $0.073 \mathrm{~m} / \mathrm{km}$ and $1.619 \mathrm{~m} / \mathrm{km}$ for MEPDG and HIPERPAV II, respectively. The increase in roughness due to decease in thickness is minimal for MEPDG. PCC thickness less than $178 \mathrm{~mm}$ is not recommended since roughness exceeds the limit while using HIPERPAV II. MEPDG and HIPERPAV II give approximately the same roughness at PCC thickness of $215 \mathrm{~mm}$. In general, roughness prediction from MEPDG is not sensitive to the change in PCC thickness.

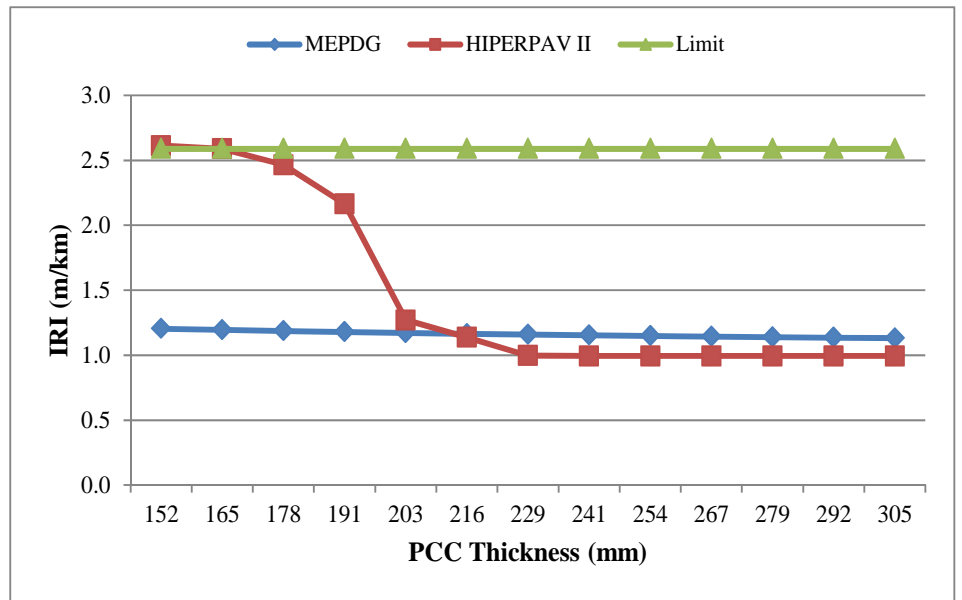

(a) IRI

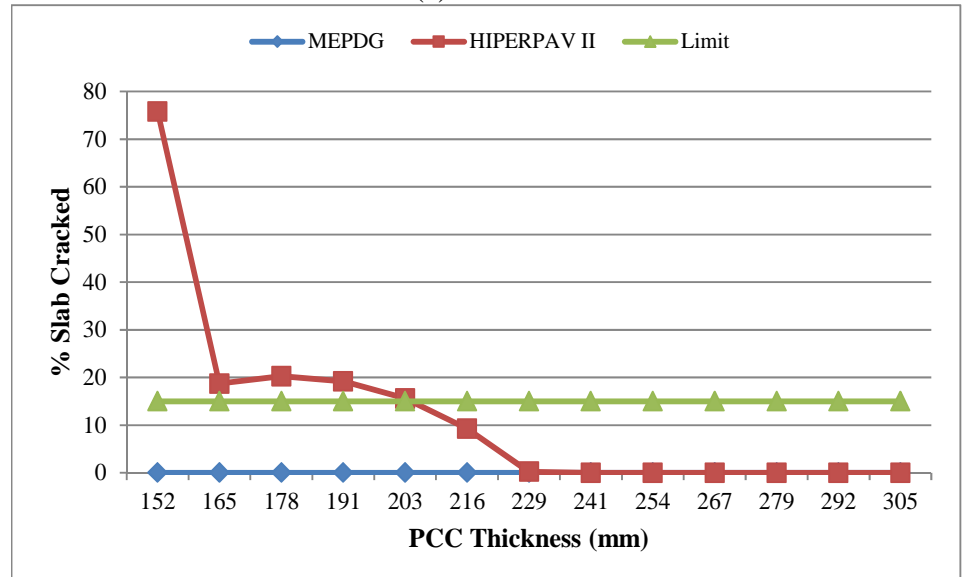

(b) Percent Slabs Cracked

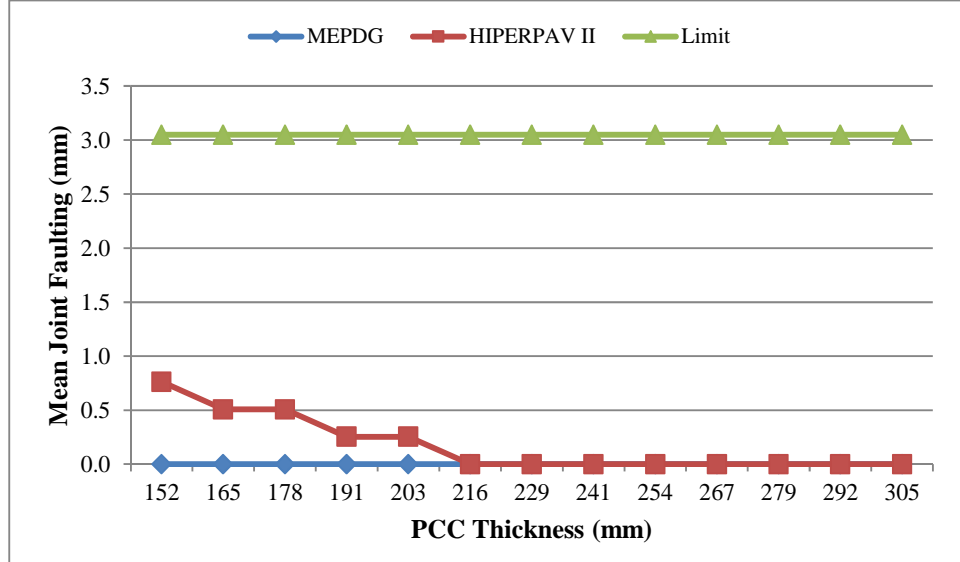

(c) Mean joint faulting

Fig. 7 Comparison of long-term JPCP performance using MEPDG and HIPERPAVII. 


\subsubsection{Percent Slabs Cracked}

Comparison of long-term performance in terms of percent slabs cracked is shown in Fig. 7(b). No crack has been observed in prediction by MEPDG, but a significant increase in cracking was observed in HIPERPAVII. Both procedures have shown no cracking up to PCC thickness of $230 \mathrm{~mm}$. The increase in percent slabs cracked due to decrease in thickness from $230 \mathrm{~mm}$ to $150 \mathrm{~mm}$ is $76 \%$. A significant increase in cracking was observed at a thickness lower than 165 mm for HIPERPAVII. PCC thickness less than 215 $\mathrm{mm}$ is not recommended as per the results by HIPERPAVII.

\subsubsection{Mean Joint Faulting}

As shown in Fig. 7(c), no joint faulting was observed for both procedures up to PCC thickness of $216 \mathrm{~mm}$. There is no faulting for the range of thickness for MEPDG, but there is an increase of faulting from zero to $0.76 \mathrm{~mm}$ when the thickness was decreased from 216 $\mathrm{mm}$ to $150 \mathrm{~mm}$ using HIPERPAV II.

\section{Conclusions}

Based on this study, the following conclusions can be made:

Both upward and downward curling increase as the temperature gradient increases. Based on the results, a maximum temperature gradient of $12^{\circ} \mathrm{C}$ appears to be reasonable for typical PCC pavements in Kansas.

Curling resulting from a particular positive temperature differential is slightly higher than that resulting from the negative temperature differential of the same magnitude.

The maximum stresses resulting from the combined effect of curling and traffic loading due to a positive temperature differential are higher than those due to the negative temperature differential of same magnitude. This should be considered in the pavement design as is done in MEPDG.

Assumption of linear temperature distribution across the slab thickness results in lower curling deflection than that due to nonlinear distribution. The difference between the deflection values is less than $10 \%$.

Curling deflections measured in the field are in close agreement with the deflections obtained from the FE simulation for lower temperature differentials.

MEPDG and HIPERPAV II analysis showed about similar performance for the PCC thickness ranging from $300 \mathrm{~mm}$ to $215 \mathrm{~mm}$. The optimum PCC thickness for this project has been found to be $215 \mathrm{~mm}$ from both procedures.

\section{Acknowledgments}

The authors wish to thank Dr. Xiao Xin of the Department of Mechanical and Nuclear Engineering at Kansas State University for help during different stages of the FE simulation. They would also like to thank Mr. Paul Lewis of Kansas State University, who helped during curling data collection.

\section{References}

[1] ACI Committee 116.1978, Cement and Concrete Terminology, SP-19(78), American Concrete Institute, Detroit, Michigan, ANSYS, 2003, Structural Analysis Guide, ANSYS, Inc., Pennsylvania.

[2] T. Tang, D. G. Zollinger and S. Senadheera, Analysis of concave curling in concrete slabs, Journal of Transportation Engineering 119 (4) (1993) 18-32.

[3] M. Emborg, Thermal stresses in concrete structures at early ages, Ph.D. Dissertation, Lulea University of Technology, Lulea, Sweden, 1989.

[4] C. A. Beckemeyer, L. Khazanovich and H. T. Yu, Determining amount of built-in curling in jointed plain concrete pavement, Journal of Transportation Research Board 1809 (2002) 85-92.

[5] Y. H. Huang, Pavement Analysis and Design (2nd ed.), Prentice Hall, Inc., NJ, 2004.

[6] C. R. Byrum, Analysis of LTPP JCP slab curvature using high speed profiles, Journal of Transportation Research Board 1730 (2000) 1-9.

[7] B. Choubane and M. Tia, Nonlinear Temperature Gradient Effect on Maximum Warping Stresses in Rigid Pavements, in: Transportation Research Record: Journal of Transportation Research Board 1370 (1992) 11-19.

[8] J. Zhang, T. W. Fwa, K. H. Tan and X. P. Shi, Model for nonlinear thermal effect on pavement warping stresses, Journal of Transportation Engineering 129 (6) (2003) 695-702. 
[9] E. J. Yoder and M. W. Witczak, Principles of Pavement Design, Wiley, NY, 1975.

[10] Button, Dallas Semiconductor Corporation, 2003, available online at: http://www.ibutton.com.

[11] C. Channnakeshava, F. Barzegar and G. Z. Voyiadjis, Nonlinear FE analysis of concrete pavements with doweled joints, Journal of Transportation Engineering 119 (5) (1993) 763-781.

[12] W. G. Davis, G. M. Turkiyyah and J. P. Mahoney, Ever FE: Rigid Pavement Three-Dimensional Finite Element Analysis Tool, Journal of Transportation Research Board 1629 (1998) 41-49.
[13] C. M. Kuo, Three-dimensional finite element analysis of concrete pavement, Ph.D. Dissertation, University of Illinois, Illinois, 1994.

[14] NCHRP, Guide for Mechanistic-Empirical Design of New and Rehabilitated Pavement Structures: Final Report for Project 1-37A, Transportation Research Board, National Research Council, Washington, D.C., 2004.

[15] B. F. McCullough and R. O. Rasmussen, Fast-Track Paving: Concrete Temperature Control and Traffic Operating Criteria for Bonded Concrete overlays, Vol. II - HIPERPAV User's Manual, FHWA Report FHWA-RD-98-168, Federal Highway Administration, U.S. Department of Transportation, 1999. 